\title{
Comparative Cost Efficiency of the Originator Drug of Infliximab and its Biosimilar for the Treatment of Rheumatoid Arthritis in the MENA Region
}

\author{
Ammar Almaaytah ${ }^{1, *}$, Feras Darwich Elhajji ${ }^{2}$ \\ 'Department of Pharmaceutical Technology, Faculty of Pharmacy, Jordan University of Science and Technology, Irbid, JORDAN. \\ 2Department of Clinical Pharmacy and Therapeutics, Faculty Pharmacy, Applied Science Private University, Amman, JORDAN.
}

\begin{abstract}
Objectives: To study and assess the comparative cost efficiency of Infliximab's originator (Remicade ${ }^{\circledR}$ ) and its biosimilar (Remsima ${ }^{\circledR}$ ) in the treatment of Rheumatoid Arthritis (RA) across seven Middle Eastern and Northern African countries including Saudi Arabia, Jordan, Morocco, UAE, Tunisia, Algeria and Iraq. Methods: Direct costs incurred by one patient for the treatment of moderate to severe RA according to clinical practice were calculated with a treatment regimen consisting of the recommended initial dose of infliximab which is $3 \mathrm{mg} / \mathrm{kg}$ every 8 weeks after taking initial loading doses at weeks 0,2 and 6 . The budget impact analysis also depended on two different scenarios. The first scenario disallows the interchangeability between Remicade ${ }^{\circledR}$ and Remsima ${ }^{\circledR}$ during the treatment duration, while the second scenario assumes interchangeability after 6 months of treatment from the infliximab's originator to its biosimilar. Results: The cumulative cost for treatment with the originator infliximab (Remicade ${ }^{\circledR}$ ) and its biosimilar Remsima ${ }^{\circledR}$ for the three-year period was $27054.00 \$$ and $21384.00 \$$, respectively and according to the first treatment scenario. For the second scenario which assumes interchangeability, the total 3 year cost for both Remicade ${ }^{\circledR}$ and Remsima ${ }^{\circledR}$ was $27054.00 \$$ and 22335.30 $\$$, respectively. The overall cost savings over three years ranged between
\end{abstract}

$17.4-21 \%$ for the two simulated scenarios. Conclusion: Our study displayed that employing Infliximab's biosimilar $\left(\operatorname{Remsima}^{\circledR}\right)$ for the treatment of RA makes a significant decrease in the overall cost of treatment incurred by the patient (or the payer). Our results clearly highlight that employing Infliximab's biosimilar, Remsima ${ }^{\circledR}$, for the treatment of RA in the MENA regions would provide significant savings both for the patient or the institutional health care organizations responsible for covering the cost of therapy.

Key words: Rheumatoid arthritis, Biosimilars, Infliximab, Budget impact analysis, Cost Efficiency.

\section{Correspondence}

Dr. Ammar Almaaytah, Associate Professor, Department of Pharmaceutical Technology, Faculty of Pharmacy, Jordan University of Science and Technology, Irbid-21110, JORDAN.

Phone: +962777658820

Email: amalmaaytah@just.edu.jo

DOI: 10.5330/ijpi.2019.1.4

\section{INTRODUCTION}

Rheumatoid Arthritis (RA) is a chronic progressive inflammatory disease that is involved in targeting the middle-aged population resulting in sustained destruction and inflammation of the synovial joints located around the knees, hands and wrists. ${ }^{1}$ RA manifests itself with affected individuals experiencing pain, stiffness, swelling and eventually functional joint disability. ${ }^{2}$ Additionally, patients not treated for RA can have devastating effects on their quality of life as the progressive joint destruction leads to physical disability accompanied by co-morbid conditions such as infections, cancer and sepsis ${ }^{3}$

Therapeutic management options for patients with RA depend mainly on the use of Disease-Modifying Antirheumatic Drugs (DMARDs). ${ }^{4}$ These agents are characterized by their ability to reduce and even reverse the manifestations of the disease and enhance the quality of life of RA patients. ${ }^{5}$ Recently the DMARDs have been classified into two classes: the synthetic chemical DMARDs including agents such as methotrexate, sulfasalazine and tofacitinib while the other class, the so-called biological DMARDs includes the TNF-alpha inhibitors (adalimumab, certolizumab pegol, etanercept, golimumab and infliximab) and the immunomodulators (rituximab, tocilizumab and anakinra). ${ }^{6}$

Infliximab is a genetically engineered chimeric monoclonal antibody that targets soluble and membrane bound TNF- $\alpha$, thus preventing the molecule from binding to its receptors and initiating the pro-inflammatory signaling cascade that is responsible for the inflammatory episodes associated with RA. ${ }^{7}$ In RA, Infliximab is approved for the management of the moderate to severe forms of the disease in combination with methotrexate. ${ }^{8}$ Patients with active RA and receiving Infliximab with methotrexate achieve better clinical outcomes including the reduction of clinical signs and symptoms of the disease, halting the progression of joint damage and enhancing the quality of life of RA patients. ${ }^{9}$ The AntiTumor Necrosis Factor Trial in Rheumatoid Arthritis with Concomitant Therapy (ATTRACT), is a double blind clinical trial of the originator infliximab (Remicade ${ }^{\oplus}$ ) in combination with methotrexate versus monotherapy with methotrexate for RA have shown a significant reduction in the clinical signs and symptoms of the disease in parallel with slowing the progression of joint damage. ${ }^{10}$ The recommended initial dose of infliximab for the treatment of RA is $3 \mathrm{mg} / \mathrm{kg}$ every 8 weeks with an initial loading dose at weeks 0,2 and 6 (i.e. $24 \mathrm{mg} / \mathrm{kg}$ in the first year and then $18 \mathrm{mg} / \mathrm{kg}$ in each of the next two years).

Biosimilars are defined as similar versions of the originator biological drugs that have proven through rigorous comparability exercise to be of a high degree of similarity with the original biological drug. ${ }^{11}$ The European Medicines Agency (EMA) was the first regulatory authority to introduce clear regulatory guidelines regarding biosimilar approval and registration. ${ }^{12}$ These guidelines depend on the ability of the manufacturer of the biological copy to demonstrate high similarity to the reference 
product in terms of quality, safety and pre-clinical and clinical efficacy. ${ }^{13}$ The first infliximab bio similar to be approved by the EMA and the U.S FDA and received market authorization for the all indications related to the originator infliximab (Remicade ${ }^{\circledR}$ ) was CT-P13, later named (Remsima', Celltrion Healthcare, South Korea).

In the Middle East and North Africa, most countries have adopted or are currently in the process of adopting regulatory guidelines regarding the registration and approval of biosimilars. These regulatory guidelines are mainly adopted from the WHO and EMA guidelines and require drug manufacturers to provide a systematic comparability exercise for the biosimilar against its originator in order to be approved in those countries. Budget Impact Analysis (BIA) or what is known as comparative cost efficiency studies focus on measuring the direct costs that the patient or buyer would incur if they are required to undertake different alternative treatments, these studies are not performed to measure the clinical outcomes of different treatment choices but rather to estimate the direct cost attributed to a certain therapeutic choice. ${ }^{14}$ BIA offers clinical practitioners, patients and governmental authorities responsible for drug procurement important data regarding the decisions to be made for treatment adoption. The aim of this study is to perform a cost comparative efficiency study between Remicade and its biosimilar Remsima in the MENA region. The analysis will depend on calculating the cost of each of these therapies employing a three-year treatment regimen of infliximab as recommended by clinical practice for patients with RA.

\section{MATERIALS AND METHODS}

\section{Cost modelling framework}

The cost comparative efficiency study focused on seven MENA countries, namely Saudi Arabia, Jordan, Morocco, UAE, Tunisia, Algeria and Iraq. According to the recent population consensus of 2016 for these countries, the total population of all seven countries is estimated to be $177,216,415$ distributed as the following: 33,554,343 in Saudi Arabia (proportional coefficient $(\mathrm{PC})=0.189), 9,903,802$ in Jordan $(\mathrm{PC}=0.0558), 35,276,786$ in Morocco ( $\mathrm{PC}=0.199), 9,269,612$ in $\mathrm{UAE}(\mathrm{PC}=0.0523), 11,403,248$ in Tunisia $(\mathrm{PC}=0.0643), 40,606,052$ in Algeria $(\mathrm{PC}=0.229)$ and $37,202,572$ in Iraq $(P C=0.209)$. The cost model in this study depends on the direct purchasing costs that the patient (or the payer) would incur when treated with either Remicade or Remsima over a 3-year treatment cycle according to the current clinical practice. The budget impact analysis also depends on two different scenarios according to a study conducted previously by Brodszky et al. ${ }^{15}$ The First scenario disallows the interchangeability between Remicade and Remsima during the treatment duration, while the second scenario assumes interchangeability after 6 months of treatment from the originator infliximab to its biosimilar. Indirect costs resulting from hospitalization, delivery and co-current treatments associated with RA therapy will not be included as the budget impact study is targeted only for direct RA treatment costs by infliximab. Accordingly and in order to calculate the costs of both agents, the official list prices of both agents in all seven countries were employed for cost calculation as a yearly treatment regimen of $21.75 \mathrm{mg} / \mathrm{kg} / \mathrm{yr}$. As Infliximab is a weight based medicine, we based our calculations on the pivotal ATTRACT trial mean body weight of the patients of $75 \mathrm{Kg}$. The Drug costs were derived from official national data price lists, as all countries listed in this study adopt a public drug pricing system.

\section{Assumptions of the model and input status}

This study is concerned with assessing the comparative cost efficiency of infliximab's originator Remicade and its approved biosimilar Remsima . The following assumptions apply to our cost model: as regulations of biosimilars worldwide including the U.S, WHO and the European Union clearly indicate that any approved biosimilar has to demonstrate a significant and clinically acceptable degree of similarity with the originator drug, it is assumed that there are no differences in both safety and efficacy between the originator and its biosimilar products as they have been approved by both the U.S FDA and the EMA. Moreover, this study has not incorporated any costs that are not direct to the absolute cost of the medications and that have any relation to certain clinical outcomes. All cost estimations have not considered differences in clinical practice (if any) between the countries included in the study, meaning that a unified standard clinical practice method was assumed. Finally, the cost estimates and analyses are current and were based on the weighted average cost of a one vial of $100 \mathrm{mg}$ Remicade and Remsima ${ }^{\circ}$, according to the population of each country. The weighted unit price was 500.59 \$ for Remicade ${ }^{\circ}$ and 395.9 \$ for Remsima (Table 1). The prices of both products were converted into U.S dollars using the international exchange rate on the $13^{\text {th }}$ of June 2018 of 1.41 U.S dollars to 1 Jordanian dinar, 0.27 U.S dollars for 1 Saudi Riyal, 0.27 U.S dollars for 1 UAE dirham, 0.008 U.S dollars to 1 Algerian dinar, 0.38 U.S dollars to 1 Tunisian dinar, 0.00084 U.S dollars to 1 Iraqi dinar and 0.11 U.S dollars to Moroccan dirham, respectively.

\section{Analysis}

The cost was calculated for a 3-year treatment period divided on a yearly quarter basis with both Remicade and Remsima. The analysis was based on the yearly treatment regimen of infliximab in RA of $(24 \mathrm{mg} / \mathrm{kg} / \mathrm{yr})$ and based on the mean body weight of the patients included in the pivotal ATTRACT trial, of $75 \mathrm{Kg}$. This was applied to both scenarios included in the budget impact study.

\section{RESULTS}

Table 2 displays the overall cost data over the first year period based on a quarterly basis in addition to both the second and third year of treatment and the cumulative overall cost of employing both therapeutic scenarios in the study. The cumulative cost for treatment with the originator infliximab (Remicade) and its biosimilar Remsima over the first year was 9018.00 \$ and 7128.00 \$, respectively in the first clinical scenario. The cumulative cost for the three-year period in the same scenario of both Remicade and Remsima was 27054.00 \$ and 21384.00 \$, respectively. The first clinical scenario compares the cost of both products on a head-to-head basis for the whole duration of treatment. The amount of savings incurred from employing Remsima instead of its originator were 1888.00 \$ per patient for the first year of treatment, which translates into an approximately $21 \%$ reduction in the cost of treatment when Remsima

Table 1: Retail prices and the weighted unit price (U.S Dollars) for a $100 \mathrm{mg}$ vial and $1 \mathrm{mg}$ for Remicade and Remsima in MENA countries.

\begin{tabular}{ccc} 
& \multicolumn{2}{c}{ Retail Price (U.S Dollars) for 100 mg of Infliximab } \\
\cline { 2 - 3 } Country & Remsima $^{\circ}$ & Remicade $^{\circ}$ \\
\hline Morocco & 466 & 640 \\
Algeria & 336 & 436 \\
Tunisia & 420 & 520 \\
Iraq & 315 & 450 \\
Jordan & 508 & 603 \\
United Arab Emirates & 418 & 643 \\
Saudi Arabia & 440 & 416 \\
Weighted Unit & $\mathbf{3 9 5 . 9 0}$ & $\mathbf{5 0 0 . 5 9}$ \\
Price/100 mg & & \\
Weighted Unit & $\mathbf{3 . 9 6}$ & $\mathbf{5 . 0 1}$ \\
Price/1 mg & & \\
\hline
\end{tabular}


Almaaytah and Elhajji.: Cost Comparative Analysis of Infliximab in RA

Table 2: Total direct costs of employing Remicade ${ }^{\circ}$ and Remsima over a 3-year period with two different clinical scenarios.

\begin{tabular}{ccccccc}
\hline \multicolumn{7}{c}{ Budget impact (\$) } \\
\hline \multicolumn{7}{c}{ Scenario 1 } \\
\hline Brand name & Q1 & Q2 & Q3 & Year 1 & Year 2 & Year 3 \\
\hline Remicade & 3381.00 & 5635.00 & 6762.00 & 9016.00 & 15778.00 & 22540.00 .00 \\
Remsima & 2673.00 & 4455.00 & 5346.00 & 7128.00 & 12474.00 & 17820.00 \\
\hline Brand name & Q1 & Q2 & Q3 & Year 1 & Year 2 & Year 3 \\
\hline Remicade & 3381.00 & 5635.00 & 6762.00 & 9016.00 & 15778.00 & 22540.00 .00 \\
Remicade $/$ Remsima & 3381.00 & 5635.00 & 6526.00 & 8308.00 & 13654.00 & 19000.00 \\
Switch & & & & & & \\
\hline
\end{tabular}

Table 3: Cumulative savings of employing Infliximab's biosimilar over a 3-year period in U.S dollars in two different clinical scenarios.

\begin{tabular}{cccc}
\hline \multicolumn{4}{c}{ Cumulative Savings (\$) } \\
\hline Clinical Scenario & Year 1 & Year 2 & Year 3 \\
\hline Scenario 1 & 1888.00 & 3304.00 & 4720.00 \\
Scenario 2 & 708.00 & 2124.00 & 3540.00 \\
\hline
\end{tabular}

is use instead of Remicade. The amount of cumulative savings for the three-year period reaches $4720.00 \$$ per patient and equals the cost of 5.3 doses of Remsima. In other word, it can cover the treatment costs of one patient over more than 8 months when employing Infliximab's biosimilar Remsima" (Table 3). Saving can also be noted when following the second clinical scenario where the patient in switched from Remicade to Remsima after 6 months of treatment. The total cost of both Remicade and Remsima over a three-year period was $22540.00 \$$ and 19000.00 \$, respectively. The percentage cost reduction of employing infliximab's biosimilar Remsima accounts for around $15.7 \%$. This data, which clearly shows a significant difference in total direct cost between infliximab and its biosimilar in the MENA region clearly indicates the benefit of switching from infliximab's originator to its biosimilar in the treatment of RA. The savings that can be incurred by employing infliximab's biosimilar can offer other patients the option of being treated with biological DMARDs instead of relying on the traditional DMARDs that can offer limited clinical outcomes in clinical practice.

\section{DISCUSSION}

The findings of our comparative cost efficiency study indicate that employing the biosimilar of infliximab in treatment of RA in the MENA region will yield beneficial cost savings to the direct buyer as displayed in our two clinical scenarios. Additionally, our results clearly demonstrate that treatment with the originator of Infliximab is higher in cost than its biosimilar reaching a percentage savings of $21 \%$ when adopting infliximab's biosimilar. The total weighed unit retail price of Remsima ${ }^{\oplus}$ in the MENA region is less by $21 \%$ than its originator Remicade ${ }^{\circ}$. When employed for a three-year duration of treatment, this would translate into 7.5 months of therapy for another RA patient due to biosimilar use and adoption by public health authorities. Biosimilars are supposed to offer notable cost savings and are considered as biological generics; our data displays a significant reduction the total cost of treatment due to biosimilar use, this data is consistent with most biosimilar comparative cost efficiency studies that offer an average of $20-30 \%$ reduction in the total direct costs related to the biological originator. ${ }^{16} \mathrm{~A}$ recent budget impact analysis study for infliximab and the same biosimilar (Remsima") in six central and east European countries for the treatment of RA have clearly demonstrated substantial savings that could be reinvested in the treatment of other patients in need of treatment of the relatively expensive biological treatment. ${ }^{15}$ Another budget impact analysis study looked at the amount of savings generated in the UK, Italy, France and Germany with the use of a minimum $10 \%$ discount on infliximab's biosimilar and achieved substantial cost savings for the biosimilar switch. ${ }^{17}$ Although our data clearly substantiates the cost saving associated with biosimilar use, we believe that the cost reduction can be increased with the re-evaluation of the pricing strategy of both biosimilar drug manufacturers and local pricing regulatory authorities in the MENA region. As most physicians are still hesitant to employ biosimilars in place of their originators for the treatment of different disease modalities, a more cost incentive based strategy should be pursued to increase biosimilar use and consequently offer these novel therapeutics for a larger portion of patients who are in desperate need of such innovative therapeutic options. A recent survey about the familiarity and of biosimilars within physicians in the Middle East region have demonstrated low awareness and cautiousness towards biosimilars within health practitioners in the region. ${ }^{18}$ This reinforces our suggestion to further reduce the price of biosimilars and encourage more physicians and health practioners to adopt these medications.

The aim of our study was to assess the degree of savings utilized from infliximab's biosimilar utilization in the MENA region which would in turn be translated into longer treatment periods for individual patients or an increase in Biological DMARDs patient recruitment. Our data clearly highlights the incentives of biosimilar use and should encourage clinical practitioners, patients and governmental authorities responsible for drug procurement to adopt infliximab's biosimilar use in RA. As the growth of biosimilars is forecasted to grow in the future, more encouraging data will emerge that will reinforce the logic behind employing biosimilar therapeutics for clear benefits in regards to their cost, efficiency and safety.

\section{CONCLUSION}

In conclusion and as more biosimilars are currently undergoing the approval process in the MENA region, we propose a reevaluation of the pricing approach to be adopted by biosimilar manufacturers and the governmental pricing agencies in order to allow proper pricing incentives for biosimilar use and adoption in the clinic

\section{ACKNOWLEDGEMENT}

This work was supported by the Deanship of research at Jordan University of Science and Technology. 


\section{CONFLICT OF INTEREST}

The authors declare that there is no conflict of interest regarding the publication of this article.

\section{ABBREVIATIONS}

RA: Rheumatoid Arthritis; MENA: Middle East and North Africa; DMARDs: Disease Modifying Antirheumatic drugs; TNF- $\alpha$ : Tissue Necrosis Factor Alpha; EMA: European Medicines Agency; FDA: Food and Drug Administration; WHO: World Health Organization; BIA: Budget Impact Analysis; UAE: United Arab Emirates; PC: Proportional Coefficient; UK: United Kingdom.

\section{REFERENCES}

1. Mjaavatten MD, Bykerk VP. Early rheumatoid arthritis: The performance of the 2010 ACR/EULAR criteria for diagnosing RA. Best Pract Res Clin Rheumatol. 2013;27(4):451-66.

2. Padyukov L, Lampa J, Heimbürger M, Ernestam S, Cederholm T, et al. Genetic markers for the efficacy of tumour necrosis factor blocking therapy in rheumatoid arthritis. Ann Rheum Dis. 2003;62(6):526-9.

3. Kiely PD, Chris D, Josh D, Östör AJK. Biologic agents for rheumatoid arthritisnegotiating the NICE technology appraisals. Rheumatology. 2011;51(1):24-31.

4. Kvamme MK, Elisabeth L, Till U, Tron AM, Tore KK, Ivar SK. Cost-effectiveness of TNF inhibitors vs synthetic disease-modifying antrheumatic drugs in patients with rheumatoid arthritis: A Markov model study based on two longitudinal observational studies. Rheumatology. 2015;54(7):1226-35.

5. Smolen JS, Daniel A, Marcus K, Weisman MH, Paul E. New therapies for treatment of rheumatoid arthritis. The Lancet. 2007;9602(370):1861-74.

6. Smolen JS, Robert L, Johannes B, Gerd B, Katerina C, Maxima D, et al. EULAR recommendations for the management of rheumatoid arthritis with synthetic and biological disease-modifying antirheumatic drugs: 2016 update. Annals of the Rheumatic Diseases: Annrheumdis-2016. 2017;17(6):960-77.

7. Janssen Biotech Inc. Remicade prescribing information www.remicade. $\mathrm{com} / \mathrm{shared/product/remicade/prescribing-information.pdf.} \mathrm{last} \mathrm{assessed} \mathrm{on}$
27/07/2019

8. Stevenson M, Archer R, Tosh J, Simpson E, Everson-Hock E, Stevens J, et al. Adalimumab, etanercept, infliximab, certolizumab pegol, golimumab, tocilizumab and abatacept for the treatment of rheumatoid arthritis not previously treated with disease-modifying antirheumatic drugs and after the failure of conventional disease-modifying antirheumatic drugs only: Systematic review and economic evaluation. Health Technol Assess. 2016;20(35):1-610.

9. Smolen JS, Ferdinand CB, Gerd RB, Vivian B, Maxime D, Paul E, et al. Treating rheumatoid arthritis to target: 2014 update of the recommendations of an international task force. Ann Rheum Dis. 2016;75(1):3-15.

10. Maini RE, StWilliam C, Ferdinand B, Daniel F, Joachim K, Michael W, et al. Infliximab (chimeric anti-tumour necrosis factor $\alpha$ monoclonal antibody) versus placebo in rheumatoid arthritis patients receiving concomitant methotrexate: A randomised phase III trial. The Lancet. 1999;354(9194):1932-9.

11. Farhat $F$, Alfredo T, Wungki P, DeGilberto LL, Raja M, Chukwuemeka I, et al. The Concept of Biosimilars: From Characterization to Evolution-A Narrative Review. Oncologist. 2018;23(3):346-52.

12. Moorkens E, Jonker-Exler C, Isabelle H, Paul D, Steven S, Arnold G. Overcoming barriers to the market access of biosimilars in the European Union: The case of biosimilar monoclonal antibodies. Front Pharmacol. 2016;7:193.

13. Dörner T, Vibeke S, Paul C, João G, László G, Jonathan K, et al. The changing landscape of biosimilars in rheumatology. Annals of the Rheumatic Diseases: Anrheumdis-2016. 2016;75(6):974-2.

14. Sullivan SD, Josephine AM, Federico AJ, Jaime C, Karen ML, et al. Budget impact analysis_principles of good practice: report of the ISPOR 2012 Budget Impact Analysis Good Practice II Task Force. Value Health. 2014;17(1):5-14.

15. Brodszky $V$, Petra B, Orsolya B, Márta P. Budget impact analysis of biosimilar infliximab (CT-P13) for the treatment of rheumatoid arthritis in six Central and Eastern European countries. Eur J Health Econ. 2014;15(1):65-71.

16. Zelenetz AD, Islah A, Edward LB, James DC, Davenport-Ennis N, Barry DD, et al. NCCN biosimilars white paper: Regulatory, scientific and patient safety perspectives. J Natl Compr Canc Netw. 2011;9(Suppl 4):S-1.

17. Kim JJH, Alex K. Year budget impact analysis of biosimilar infliximab for the treatment of rheumatoid arthritis in UK, Italy, France and Germany. Arthritis Rheumatol. 2014;11(Suppl 1):S512.

18. Farhat F, Ahmad O, ElFadi K, Joseph K. Review and results of a survey about biosimilars prescription and challenges in the Middle East and North Africa region. Springer Plus. 2016);5(1): 2113 